\title{
TECHNOLOGICAL HIGHLIGHTS OF THE 5,050M³ BLAST FURNACES AT BAOSTEEL ZHANJIANG BASE *
}

\author{
Liao Jianfeng ${ }^{1}$ \\ Wen Huizheng ${ }^{2}$ \\ Zou Zhongping ${ }^{3}$ \\ Ao Aiguo ${ }^{4}$
}

\begin{abstract}
The Baosteel Zhanjiang $5,050 \mathrm{~m}^{3}$ blast furnaces have been built with highly independent integration and innovation technologies and represented the state of the art of the world's huge BFs. The proper of BF1 and BF2 is designed with longcampaign technology; both BFs share the same set of stockhouse, water and $\mathrm{PCI}$ systems; the BCQS serial-hopper no-bell top, TRT and blower are all local equipment as applied; four top-combustion stoves systems are matched; the BFG is cleaned by fully dry process; and the automation control system for the main process is self integrated. The BFs have been started up and performing with sound indicators. Their smooth proceedings symbolize China's huge blast furnace ironmaking technology ascending a new high.

Keywords: huge BF, self integration, technology and equipment, energy efficiency and environmental protection.
\end{abstract}

CISDI Engineering Co. Ltd., Chongqing, China CISDI Engineering Co. Ltd., Chongqing, China CISDI Engineering Co. Ltd., Chongqing, China

4 Baosteel Zhanjiang Iron \& Steel Co., Ltd., Zhanjiang, Guangdong, China 


\section{Foreword}

Baosteel Zhanjiang Base presently holds two blast furnaces in the volume of $5,050 \mathrm{~m}^{3}$ respectively. They stand up as the world's most modernized blast furnaces. CISDI Engineering Co., Ltd. (CISDI for short) undertook the complete design and package supply of some equipment. The key equipment of both BFs is made in China, realizing the process, technology and equipment independently designed and integrated by our own. They are proven up to the international top levels.

The BF1 was launched design in March 2013 and broke ground two months later. Through concerted efforts, BF1 was started up in September 2015 and BF2 in July 2016.

Herein below is the summary of the technological highlights of Zhanjiang BF1 and BF2, which indeed propel China's ironmaking progress.

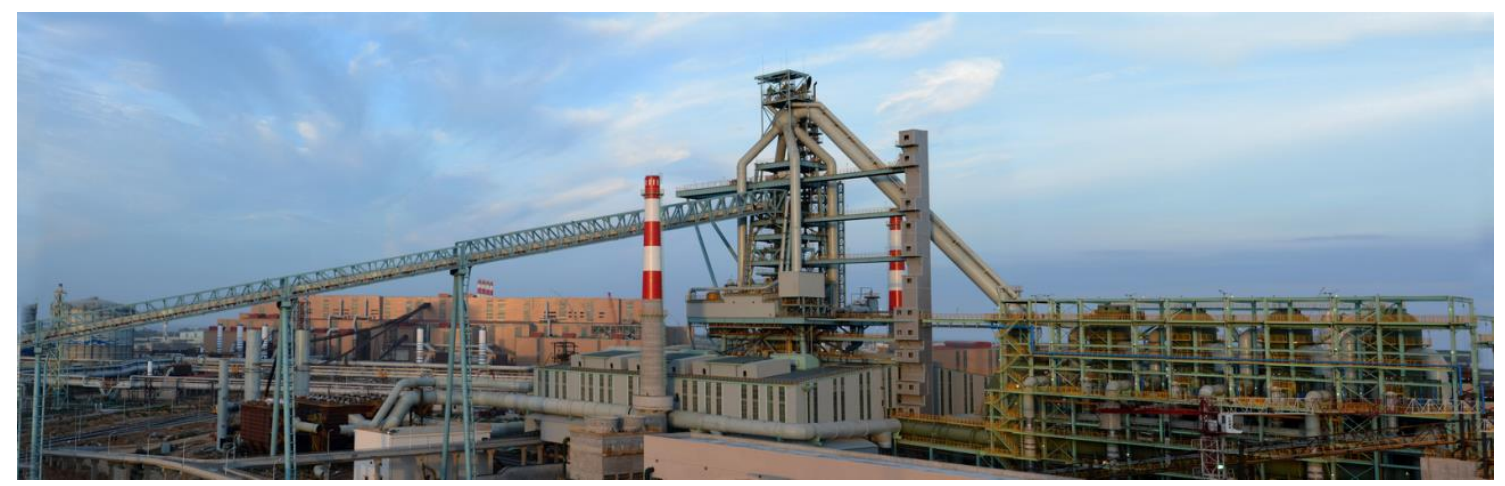

Figure 1 Picture of Zhanjiang No.1 BF

\section{Main Features of BF Process and Equipment}

(1) Both BFs share the same stockhouse system which has the parallel arrangement of ore and coke bins in common. The coke is screened in decentralized way and weighed in centralized way. The sinter and lump ore are screened and weighed in decentralized way. The undersized coke nut is recovered and mixed with ore for charge. The intermediate hopper is considered for making more flexible duty of charge and increasing the charge capacity.

(2) The serial-hopper no-bell top equipment is applied for facilitating the smooth and stable operation of blast furnace by reducing the segregation influence of distribution on the operation condition. The BCQS distributor is installed, a complete home-made equipment with the full name of Baosteel, CISDI, Qinye and Seng Quansong distributor. And the equalized gas recovery is also considered.

(3) The BF profile is designed with 3-section structure in favor of the gas flow control. The complete cast-iron cooling staves are used for improving the BF's adaptability, helped by the skillful operation. The enclosed circulating cooling system is designed, connecting the pure water piping in series. The hearth is installed with traverse castiron staves made of super micro-porous carbon blocks. The measurement and detection system is well considered. The proper is designed for a campaign life of 22 years.

(4) The casthouse is in a compact and flat style, accommodating the home-made hydraulic mud gun, drill and cover manipulator. The tuyere platform above tapholes is wide; and the elevated roadway is built for ascending the casthouse. 
(5) The drum process granulating system is applied; each casthouse is equipped with one set of drum system and dry slag pit; the steam of granulating system is vented from an 80m-high chimney to the outside air.

(6) Four (4) top-combustion stoves match the blast furnace, working in the duty of 2stove burning and 2-stove blasting, arranged in parallel and switched over for the duty. The stoves can reach a blast temperature of $1,300^{\circ} \mathrm{C}$. The fume excess heat recovery system is installed; the preheating stove is preposed for further increasing the temperature of combustion air.

(7) The pulverized coal injection ( $\mathrm{PCl}$ ) system is designed with parallel hoppers plus header and front distributor. The designed coal ratio is $220 \mathrm{~kg} / \mathrm{t}$ and the pulverization capacity is $250 \mathrm{~kg} / \mathrm{t}$.

(8) The gas cleaning system is of a dry-way process using bag filter. The largediameter bags are installed and the gas comes in and out from the top side of the system. This design is conducive to both an even distribution of gas flow and more convenient access to equipment operation and maintenance.

(9) The TRT as used for the Zhanjiang BFs is China's $1^{\text {st }}$ home-made of its kind for the huge BF in the volume level of $5,000 \mathrm{~m}^{3}$. Multiple new technologies are contained in the TRT equipment.

(10) The blower station is equipped with three (3) sets of AV-100 axial compressors with adjustable inlet stationary blades. The No.1 and 2 blowers are imported from MAN while the No.3 blower is made by Shangu (Shanxi Blower Co., Ltd.). The motors of the blowers are all products of TMEIC in Japan.

(11) The blast furnace proper is designed with pure-water enclosed circulating cooling system; the secondary cooling system works by plate-type heat exchanger. The industrial water of blast furnace is consumed by $270 \mathrm{~m}^{3} / \mathrm{h}$, and the water consumption of per unit product is $0.56 \mathrm{~m}^{3} / \mathrm{t}$.hot metal.

(12) The dedusting system of casthouse and stockhouse is bag filters and a roof deduster, bettering the casthouse environment; the ore and coke bins are separately equipped with dedusting system for effective recovery and reuse of the dusts.

(13) The automation system is configured as per individual area and different levels. The L1, L2 and MES compose the automation system for a continuous and distributed control of the process.

(14) The BF top equipment, stoves, gas cleaning and blast dehumidification system are all supplied by CISDI on EP mode.

\section{Main Technological Parameters}

Please refer to Table 1 for the Zhanjiang BFs' main technological parameters.

Table 1 - Main Technological Parameters of Zhanjiang BFs

\begin{tabular}{|c|l|c|c|c|}
\hline S/No. Item & Unit & Parameter & Remarks \\
\hline 1 & BF effective volume & $\mathrm{m}^{3}$ & 5,050 & \\
\hline 2 & Annual output of hot metal for downstream steelmaking & $10^{3} \mathrm{t}$ & 4,115 & \\
\hline 3 & Productivity $\left(\mathrm{P}_{100}\right)$ & $\mathrm{t} /\left(\mathrm{m}^{3} \cdot \mathrm{d}\right)$ & 2.280 & Max. 2.5 \\
\hline 4 & Daily output of hot metal $\left(\mathrm{P}_{100}\right)$ & $\mathrm{t}$ & 11,514 & $\mathrm{Pmax}=12,625$ \\
\hline 5 & Fuel ratio & $\mathrm{kg} / \mathrm{t}$ & 498 & \\
\hline 6 & Coke ratio & $\mathrm{kg} / \mathrm{t}$ & 278 & \\
\hline 7 & Coal ratio & $\mathrm{kg} / \mathrm{t}$ & 220 & \\
\hline 8 & Blast temperature & ${ }^{\circ} \mathrm{C}$ & 1,300 & \\
\hline 9 & Top pressure & $\mathrm{MPa}$ & 0.3 & \\
\hline
\end{tabular}




\section{Enhancing China's BF Competitiveness by Lowering Cost while Upgrading Efficiency}

The blast furnace ironmaking system is so complicated that poses high requirements on the related process, equipment and control. It had to import some key and core equipment for achieving the demanding, because the technologies monopolize of advanced oversea supplier. That increased the investment and operation costs of steel plant on one hand, and embarrassed the improvement of product competitiveness on the other. To that end, CISDI and Baosteel made joint efforts to developing a series of latest technologies and applied them to the Zhanjiang BFs. It's resulted in saving the project costs while leading China's huge BF technological indicators up to the world's top levels. It marks a great leap forward of China's blast furnace technology atop the global rank.

\subsection{Optimized General Design}

Zhanjiang Steel is nicknamed as "another starting business" of Baosteel Group, pursuing a stringent control on cost. CISDI optimized the general design and insisted on the concept of reflecting highly-efficient production throughout the design.

The design of Zhanjiang BFs had stuck to the ideal of applying mature, reliable and appropriate technology and equipment. Simulation means had been resorted to. For instance, the hot metal transport was made simulation analysis and gained the result of shortening the average transport distance of torpedo car to 900 meters, which worked the world record of short-distance transport of hot metal by torpedo car for a large blast furnace. Correspondingly, the logistics, energy consumption and operation costs got saved to a large degree. The optimization also minimized the investment per unit of furnace volume. CISDI had organized the experts to search the seaside conditions for construction of steel plant and verify the trial experience and solutions to the local complicated geology, usual suffering of typhoons and storms and proof of humid and corrosive weather conditions. The advanced technologies against typhoon and corrosion were successfully applied to ensuring the construction efficiency, practicability and safety.

To strictly control the investments, CISDI and Baosteel made reiterated reviews on multi-version feasibility studies and preliminary designs. Experience of the construction and production of four of Baosteel Shanghai blast furnaces was borrowed in for optimizing the process plan of Zhanjiang blast furnaces, in the prerequisite of concluding a feasible process proposal. At last, the casthouse area was reduced by over $1,000 \mathrm{~m}^{2}$; the full cast-iron staves were finalized after multiple comparisons with and optimizations of the combined copper and cast-iron staves. All these measures worked effectively to reduce the total investment of the project. Such bold and resolute optimizations were absolutely not assumptions but hard-won verified conclusions.

\subsection{Optimized BF Profile}

The Zhanjiang BFs were approached the profile design on the basis of experience of Baosteel Shanghai BF3; the dual-stack-angle was adopted for matching the gas flow with the burden movement; the stack could hereby be more adaptable to the gas flow change during operation; as a result, the furnaces have been running more stably. Zhanjiang BF1 has stood firmly against Mujigae typhoon and withstood the test of several regular downtimes since its startup. The cast-iron staves and dual-stackangle had contributed well to the quick resumption of production of the blast furnace. 


\subsection{Optimized BF Cooling System}

Baosteel Shanghai BF3 tells that the full cast-iron staves have been safely running for 19 years for the sake of its own strength. Concretely speaking, the full cast-iron staves are easily operated and they are conveniently recovered even if the furnace fails to run smoothly. With the improvement of manufacturing quality and maintenance craft, the cast-iron staves can be repaired back to normal quickly by a planned shutdown even if they get damaged in the later stage of furnace campaign life. It's found in the furnace practice that the copper staves are subject to leading to wall accretion and the skull tends to fall off that embarrasses the control of edge gas flow. The furnace operation becomes more sensitive to the influential factors and more difficult to be regulated. Through reiterated studies and verifications, the full cast-iron staves are selected for facilitating the operation while reducing investment cost.

Zhanjiang BFs are applied serially-connected cooling water system. It is less in the total water quantity but more in the individual pipe's water volume; that serial connection of water pipeline creates higher cooling efficiency while saving investment cost.

The pure water system I is designed for cooling the bottom water-cooled piping, hearth horizontal staves and bosh-to-throat staves, and degassed by the top degassing tank before returning to pump station. The system is divided into three sections in heights, which are in serial connections, facilitating the system thermal load test and leakage inspection.

The pure water system II is designed for boosting of return water from system I. It's comprised of three branches in parallel, respectively cooling the tuyere coolers, blow pipes and stove valves.

The pure water system II is remarkably characteristic of having its inlet water completely degassed by the top degassing tank, which effectively checks the risks of boosting system operation with gas. It's proved in practice that the water temperature rise arisen from the boosting circulation cycle after degassing should never be a concern to the operation; indeed, the discharge water temperature from the pure water system II is generally $2 \sim 3^{\circ} \mathrm{C}$ higher than that of pure water system I.

\subsection{Optimized General Layout}

(1) Peninsula arrangement can make shorter transport distance of hot metal compared with the traditional arrangement. The average travel distance between blast furnace and steelmaking shops can be shortened to $900 \mathrm{~m}$, greatly reducing the temperature drop of hot metal.

(2) The rainproof facility was added at the exterior of casthouse just above the port of TPC for further controlling the temperature drop during transport of TPC.

The two BFs at Zhanjiang Base share the same central control room which is located in between and connects both BFs by the elevated passages. It's advantageous in compactness, small footprint and economical civil construction. And it also benefits in production management, needing less duty posts and centralizing the setup of production and maintenance staff.

The stockhouse, circulating water and $\mathrm{PCl}$ systems are also combined in arrangement for both BFs, evidently saving the investment and space. 


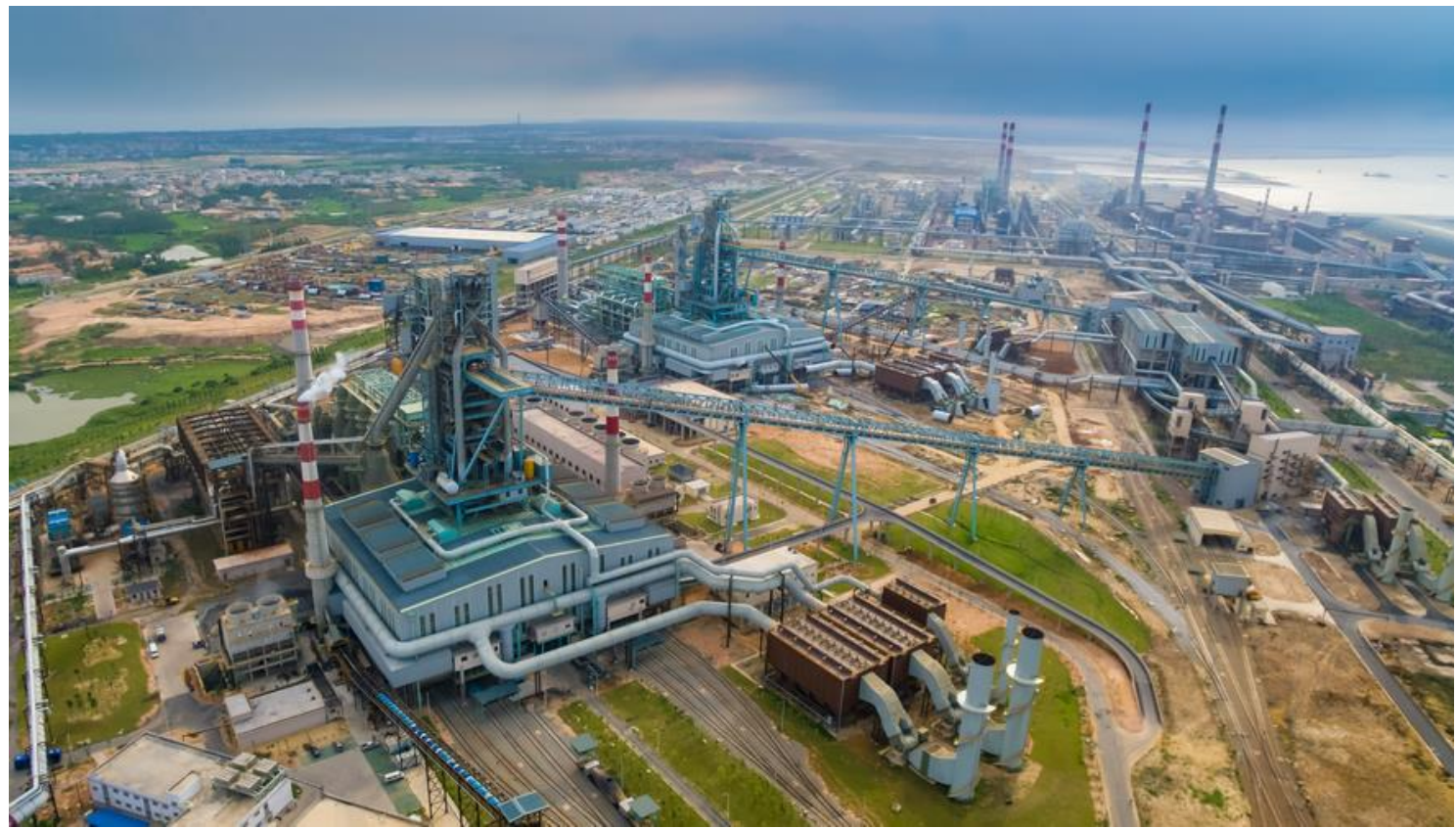

Figure 2 layout of Zhanjiang BF

\section{Major Equipment Self-integration thanks to Independent Innovation}

\subsection{No-bell Top, domestically made and environment friendly}

A research and development team was organized in 2009 including CISDI and Baosteel experts for the task of breaking foreign monopoly of large BF bell-less top technology. After more than 4 years of hard efforts, the IPR-based no-bell top technology and equipment came into reality, which could be designed and manufactured domestically. In the R\&D process, the team was committed to theoretical study, sample machine manufacture, tests on cold state, hot state and simulation distribution of machine in physical dimension; the hydraulic combined control of distributor was a breakthrough of the innovative and key technology.

The BCQS no-bell top is featured by simple structure, low fault rate and low investment compared with the imported equipment, specifically:

- Innovative distributor's hydraulic combined control technology, controlling the accuracy of distributor $\alpha$ angle within $\pm 0.1^{\circ}$, a top level in the global figures;

- Novel water-cooling and sealing structure for the distributor, resulted in high cooling strength and reliable seal; cooling water consumed by $10 \sim 15 t / h$, nitrogen consumed by below $800 \mathrm{Nm}^{3} / \mathrm{h}$, saving equipment running cost;

- The clip installation mode of distribution chute working easily for disassembly, constraining the change time within 4 hours, and saving the chute change time by beyond $1 / 2$ of the similar equipment made abroad;

- Improved guide rail structure for the distributor, replacing the original one-block rail by assembled rail, adding lubrication measures, collaborative with the distributor's triple-cylinder synch-control technology, all contributing to solving the rail wear and extending the entire service life of distributor.

The BF1 top has been performing well since its startup with the main operating data reaching the world's leading levels, proved a successful substitute for the import. The 
self-developed no-bell top for a large blast furnace has refreshed the preference of clients.

\subsection{Top-combustion Stove, independent innovation, good effects in high temperature and long campaign}

The top-combustion stove technology prevails nowadays thanks to its high temperature, low cost and stable structure. However, the external-combustion stove structure and operation mode as applied to Baosteel Shanghai BFs also excel in itself. The Zhanjiang top-combustion stoves were modified to use the vortex jet combustion and pipeline system which was usually designed for external-combustion stoves. Such combination of strengths helped form a consummate expertise of topcombustion stoves. The technical highlights are specifically described below:

The 4 stoves were designed with 4 independent mixer chambers as inspired by the concept for external-combustion stoves'. It could improve the working conditions of stove exit shell and refractory, and solve the flushing problem of pipe casing at the hot blast outlet. Besides, the temperature of hot blast main and branches got reduced hereby, improving the pipeline system structural stability and extending the service life concerned.

The self-locking assembly brick technology was applied to the ports where the stress condition and brickwork stability could be improved in practice.

The bellows and tie rod configurations were optimized by using analysis software according to the hot blast pipeline system design, and the appropriate refractory brick structures were matched to the pipeline system; all those measures could guarantee that the refractory of hot blast pipeline could run safely and for long at the temperature of $1,300^{\circ} \mathrm{C}$.

The preheating stoves were preposed and fume excess heat recovery system was postposed for realizing the blast temperature as high as $1,300^{\circ} \mathrm{C}$ in case of only burning blast furnace gas.

\subsection{Domestication of Key Equipment of Large BFs}

\subsubsection{TRT}

Each of the Zhanjiang BFs was built with a dry TRT system, which used dry axialflow reaction turbine and top-water-cooled brushless excitation synchronous generator with a nominal power of 33MW.

When the BF has a short shutdown, the TRT generator could be switched over to be a motor so as to not start or stop frequently. To secure a safe operation of TRT unit, all the safety signals should be interlocked with the rapid cut-off valves. Specifically, when one signal is given out, the rapid cut-off valve will be automatically closed and the TRT unit stops; in the meanwhile, the rapid opening valve of the reducing valve block will be simultaneously opened to stabilize the top pressure.

Although the TRT units for the most running 5,000 $\mathrm{m}^{3}$-level blast furnaces around the globe are made by MITSUI \& CO., LTD. and Kawasaki in Japan, Zhanjiang BFs are encouraged to be the initiator for use of the home-made TRT units; the domestication level of such critical equipment for a large blast furnace has been greatly enhanced.

\subsubsection{Blower Station}

The blower station of Zhanjiang BFs were installed with 3 blowers, in which, the No.3 blower was made by ShanGu in China, the $1^{\text {st }}$ of its home-made kinds for the $5,050 \mathrm{~m}^{3} \mathrm{BF}$. The blower's pneumatic and mechanical performances have reached the designed figures, and its major performance data could be comparable with those of MAN blower made in Germany. Successful application of the blower for the Zhanjiang BFs symbolized the important breakthrough of blowing technology for $5,000 \mathrm{~m}^{3}$-level BF. 


\section{Emphasis on Energy Conservation and Environmental Protection}

\subsection{Vertical Green Screen}

Zhanjiang BFs used the new-type vertical green screen for screening the sinter ore and coke, characteristic of small footprint, simple process and layout, easy change of screen net and easy maintenance. The environment-friendly screen can conduct a full screening of the materials in a high efficiency; and it's compact in structure and good at sealing effect against flying dust.

\subsection{Dry-way Gas Cleaning and Sprinkling Tower}

The dry-way gas cleaning by bag filter had been challenged by high rate of fault and unstable operation problems despite wide applications. Zhanjiang BFs were upgraded their bag filter technology and equipment based on absorptions of the past experience in Baosteel Shanghai dry-way cases.

Technically speaking, the large-diameter filters were used, with gas in and out from top, this way in favor of uniform distribution of gas flow and maintenance and operating safety; the dense-phase fluidized pneumatic transport of dust was applied to stabilize the system running and extending the dust conveyor service life; on the dust conveyor piping was installed an automatic un-blocking device to save labor; at the inner wall of clean gas piping was sprayed acid- \& moist-heat-proof coating for increasing the piping anti-corrosion performance and piping service life.

To ensure the safety of BFG holder and reduce the investment of plant-wide gas pipeline network, it took measures to control the temperature of gas pipeline network no more than $(\leqslant) 60^{\circ} \mathrm{C}$. To that end, downstream the reducing valve block and TRT was built a sprinkling tower; by means of the sprinkling tower, the clean gas temperature was lowered within the allowable range, and the chloride ion and acid substance were separated and solved in the sprinkling water; the internal grate equalizer of the sprinkling tower made an uniform distribution of gas flows; the irregular gas after decompression could directly enter the tower for buffering; the external part of tower was applied multi-layer thermal and sound insulation materials.

\subsection{Recovery of Top Equalized Gas}

The releasing of top equalized gas had become the main polluting source of dust and noise at the BF top area. Zhanjiang BFs applied CISDI-IPR-based top dry-way equalized gas recovery technology. Specifically, the top equalized gas is collected into the net gas pipeline downstream sprinkling tower after it's recovered by the cyclone deduster and equalized gas recovery device. It's a good way of waste-toenergy and decrease of carbon and dust emissions, correspondingly saving cost. Generally, $85 \%$ of the equalized gas can be recollected, that is, each blast furnace as applied can be reduced gas bleeding by $26 \mathrm{MNm}^{3} / \mathrm{a}$, direct $\mathrm{CO}_{2}$ emission by about $12,000 t / a$, dust discharge by about 400t/a and gaining the economic profit by about RMB2.5M yuan annually. Besides, the noise from the top releasing can be basically neglected; the silencer and other related equipment serve longer. It's a double-win means in environment and economy aspects.

\subsection{Boosting \& Relief of Stoves}

The stove's internal HP gas could be recovered by filling the discharged gas from one stove into another via the boosting and relief piping. It plays a role of alleviating fluctuation of gas volume and pressure during blasting and also recycling thermal 
and pressure energy. The operation of Zhanjiang BF1 tells that the technology brought about only $10 \mathrm{kPa}$ variation of blast pressure of the stoves.

\subsection{Cover Manipulator of Torpedo Ladle Car}

Zhanjiang BFs were considered cover manipulators for their 380t torpedo ladle cars. With the cover manipulators, the temperature drop during hot metal transport was reduced while the fume got checked, saving energy and decreasing emission. The site data tell the truth.

\subsection{Dedusting Facility}

The ore and coke bins of Zhanjiang BFs were designed with separate dedusting systems, which collected ore fines and transported them to sinter for reuse on one hand, and caught coke fines and conveyed them to coal batching bins for reuse on the other hand; the dust availability got enhanced.

At the casthouse $\mathrm{C} 1$ and $\mathrm{C} 2$ was designed one set of dedusting facility respectively. The dedusting points and air volumes had to be reasonably distributed; the dusting sources were closed without interfering the process and operation; the dedusting devices were optimized in structures and filled up with home-made quality membrane filtering materials. The dedusting systems of Zhanjiang BFs were given full display of their high performances in low-resistance, collecting efficiency and low-dust-content discharge. The relevant discharge data reached national dedicated standards. They rendered outstanding service for a green Zhanjiang with a blue sky.

\section{Production Effects of Zhanjiang BFs}

The Zhanjiang BFs have seen a growing momentum of their production indicators since startup. Specifically, the productivity reached the highest $2.37 \mathrm{t} /\left(\mathrm{m}^{3} . \mathrm{d}\right)$, fuel ratio declined to the lowest $480 \mathrm{~kg} / \mathrm{t}$, coal ratio climbed up to the highest $183 \mathrm{~kg} / \mathrm{t}$; the blast temperature peaked at $1,280^{\circ} \mathrm{C}$, and top pressure went up to the highest $0.275 \mathrm{MPa}$. Particularly, the tapholes and titling chutes at casthouse were all dedusted as desired; the main equipment has been running well. The following Figure 3 shows the monthly average productivity and blast temperature as recorded after the BF1 startup; the Figure 4 presents the data of coke ratio, coal ratio and fuel ratio thereof.

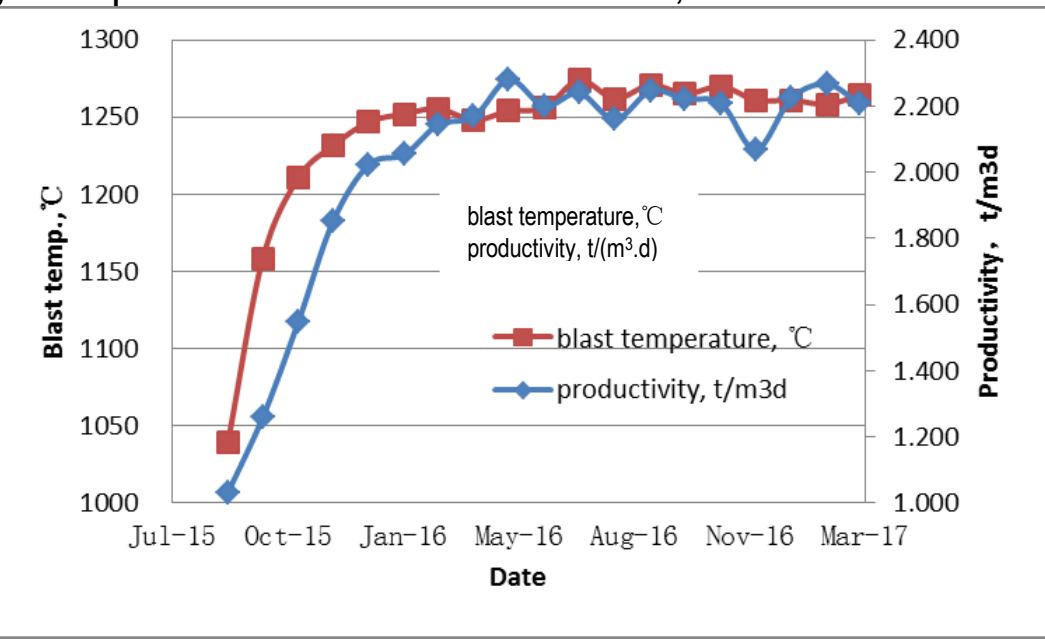

Fig. 3 - Zhanjiang BF1 Productivity and Blast Temperature 


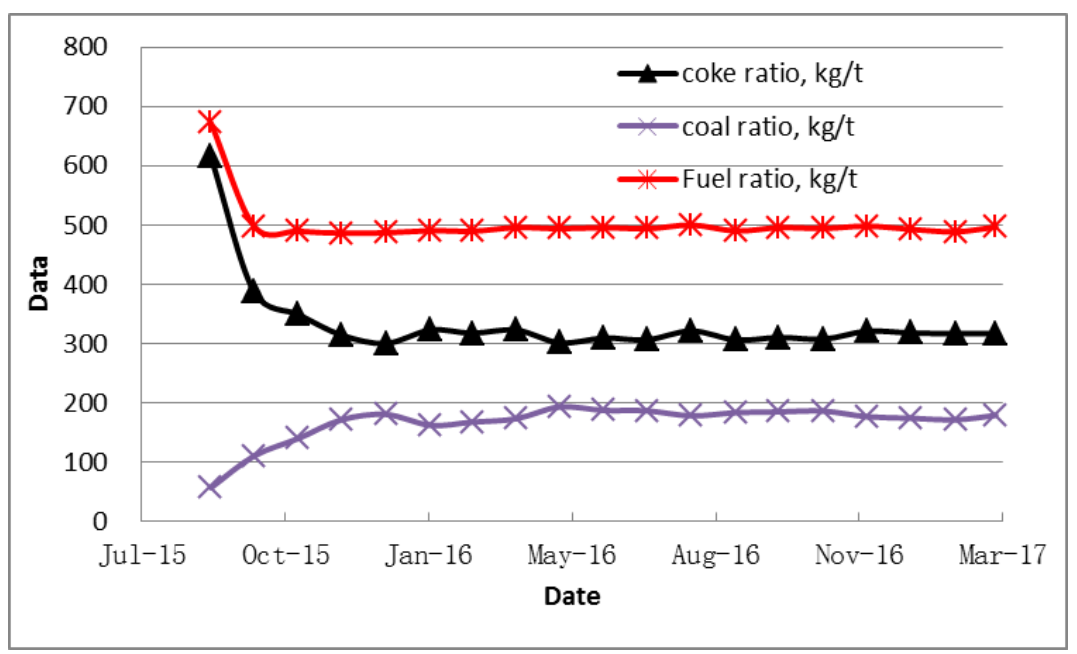

Fig. 4 - Zhanjiang BF1 Coke Ratio, Coal Ratio and Fuel Ratio

\section{Conclusion}

The Zhanjiang \#1 BF completion period is 28 months. The production data was excellent, the hot metal cost was more than 15 USD/thm lower, compared with Baosteel Shanghai base, whcih shows stronger competitiveness. 